\title{
The Study of Hole Configuration Design in Complex Block Basing on Restriction of Pressure System
}

\author{
Liu $\mathrm{Yu}^{1, \mathrm{a}}$, Wang Lihui ${ }^{1, \mathrm{~b}}$, Zhang Jinglei ${ }^{2, \mathrm{c}}$ \\ ${ }^{1}$ Petroleum Engineering Research Institute of Dagang Oilfield Company, Tianjin, 300280, China \\ ${ }^{2}$ Shallow Water Development Company of Dagang Oilfield Company, Tianjin, 300280, China \\ anepuliuyu@126.com, b790652415@qq.com, '373545227@qq.com
}

Keywords: Leakage Pressure; Changing Coefficient; hole configuration; Complex Block

Abstract. Reasonable hole configuration can avoid drilling incident. Traditional hole configuration design method can't show the necessary cementing point with complex lithology. In this paper, firstly, the four pressure calculation models and the value basis of hole configuration design coefficient and value range were introduced. Secondly, the restriction conditions for safely drilling in naked hole section were introduced. Finally, A hole configuration was designed by considering leakage pressure and changing coefficients. During drilling, there is no incident, Which can prove that the design method and coefficient range is reasonable and effective.

\section{Introduction}

The hole configuration design is one of the important design contents in drilling engineering design, and reasonable hole configuration can avoid circulation loss, blowout, collapse and sticking to the utmost extent ${ }^{[1]}$. Recently, the design methods include "top-down", "bottom-up" and "from middle to both sides" ${ }^{\text {[2, 3] }}$. Guan Zhichuan has proposed the hole configuration design and risk evaluation method considering the condition of uncertain formation pressure ${ }^{[4]}$. However, three pressure profile was used in current design method, and design coefficients are the same in the whole well. For the complex block, special lithology and abnormal pressure formation may be drilled, and the traditional method can't meet the requirements of safely drilling. In this paper, a new method basing on four pressure profiles and changing design coefficients was proposed, which can provide the basis for reasonably design hole configuration and safely drilling.

\section{The Calculating Model of Formation Pressure}

The Calculating Model of Pore Pressure. Using acoustictime normal trend line in the mud shale section with normal compression, combining Eaton formula, pore pressure can be obtained.

$$
P_{p}=P_{0}-\left(P_{0}-P_{n}\right) *\left(\frac{\Delta t_{n}}{\Delta t_{s}}\right)^{c}
$$

The Calculating Model of Caving Pressure. Choosing the Coulomb failure criteria as shear failure criterion, by mechanics changing, caving pressure calculating formula can be obtained.

$$
\left(f_{1}+\frac{1}{2} f_{2}\right) P_{w}+\frac{1}{2}\left[\left(X-Y-P_{w}\right)^{2}-4 Z^{2}\right]^{0.5}=2 \tau_{0}+0.5(X+Y) f_{2}+\left(f_{1}-f_{2}\right) \alpha P_{p}
$$

The Calculating Model of Breakdown Pressure. When drilling fluid density is too large, the tensile stress is greater than tensile strength of rock, fracture will create and lost circulation. For any wellbore conditions, breakdown pressure can be expressed as follow. 


$$
-\sigma_{t}=\frac{1}{2}\left(X+Y-P_{w}\right)-\frac{1}{2} \sqrt{\left(X+Y-P_{w}\right)^{2}+4 Z^{2}}
$$

The Calculating Model of Leakage Pressure. Leakage pressure is equal to pore pressure $\left(P_{\mathrm{p}}\right)$ plus flow pressure drop $\left(\Delta P_{c}\right)$ of drilling fluid at the near wellbore invasion area, as shown in Fig.1.

According to the model that fluid flows in capillary tube, the seepage pressure drop model of drilling fluid at invasion area can be obtained and the leakage pressure calculation model can be expressed as follow.

$$
\left.P_{1}=P_{p}+\frac{3 q_{f} \mu}{2 \pi K h} \ln \frac{r_{f}}{r_{w}}+4 \tau_{0}\left(r_{f}-r_{w}\right) \sqrt{\frac{\phi}{2 K}}\right)
$$

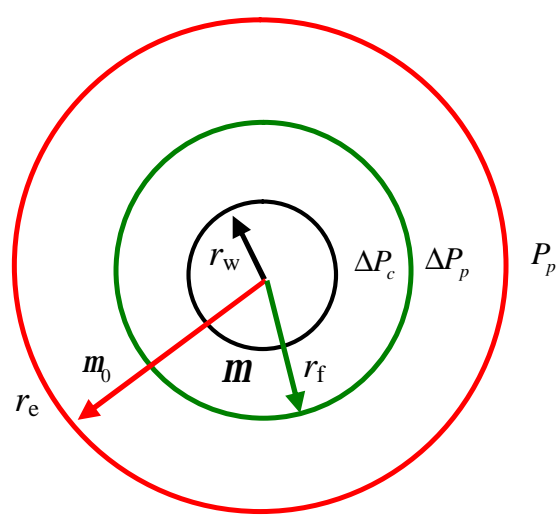

Fig.1 Leakage pressure model

\section{The Design Coefficient and Data Range}

Swabbing and Surging Pressure Coefficient. The friction calculation model of fluid flowing in circular tube and annulus is applied to the movement of the tube going through the fluid. When the tube is moving up, the friction pressure at the bottom of the tube will reduce the pressure. When the tube is moving downward, the pressure will increase.

The effective flow rate flowing through nozzle or drill string and annulus can be expressed:

$$
\overline{V_{i e}}=\bar{V}_{i}+V_{p} \quad \overline{V_{a e}}=\overline{V_{a}}+k V_{P}
$$

The friction calculation formula in string and annulus can be expressed as follow.

$$
\Delta P_{L p}=\frac{0.2 f \rho_{m} L v^{2}}{d} \quad \Delta P_{L a}=\frac{0.2 f \rho_{m} L v^{2}}{d_{2}-d_{1}}
$$

Substituting $\overline{V_{i e}}$ and $\overline{V_{a e}}$ into Eq.6, by changing $f$, making the total annulus friction equal to total pipe friction, the total annulus friction is surging pressure. According to the calculation model, the value of $S_{\mathrm{b}}$ and $S_{\mathrm{g}}$ increase with the decreasing of the space between string and borehole. The swabbing and surging pressure value are based on the maximum value in the process of tripping.

The safety coefficient of breakdown pressure. The engineering adaptability of pressure prediction result is constantly improving by conversion breakdown pressure and adjusting rock mechanics parameters. Through a lot of statistical data analysis, the accuracy of pressure prediction is more than $85 \%$, and the coincidence rate of designed drilling fluid density with actual density reaches $90 \%$. In general, the breakdown pressure safety coefficient value range is $0.03 \sim 0.06 \mathrm{~g} / \mathrm{cm}^{3}$.

Kick Tolerance. The real formation pressure can be expressed as follow.

$$
P_{p}=P_{d}+0.00981 \rho_{m} H
$$

$P_{\mathrm{d}}$ reflects the degree of underbalance, which is caused by formation pressure prediction error. The shut-in casing pressure can be expressed as follow.

$$
P_{a}+0.0098 \rho_{m}\left(H-h_{w}\right)+0.01 h_{w} \rho_{m}=P_{p}
$$

Where: $P_{\mathrm{d}}$ is shut-in pipe riser pressure, $\mathrm{MPa} ; H$ is kick depth, $\mathrm{m} ; P_{\mathrm{a}}$ is shut-in casing pressure, $\mathrm{MPa} ; \rho_{w}$ is the density of kick fluid, $\mathrm{g} / \mathrm{cm}^{3} ; \rho_{m}$ is drilling fluid density, $\mathrm{g} / \mathrm{cm}^{3} ; P_{p}$ is formation pressure, MPa; $h_{w}$ is the height of kick fluid column, $\mathrm{m}$. 


$$
P_{a}=P_{d}+0.0098\left(\rho_{m}-\rho_{w}\right) h_{w}
$$

In general, kick tolerance $\left(S_{\mathrm{k}}\right)$ is used to weight formation pressure prediction error $\left(P_{\mathrm{d}}\right)$.

$$
P_{d}=0.0098 S_{k} H
$$

$S_{\mathrm{k}}$ can used to express the risk of kick. Under present pressure prediction accuracy, the value range of $S_{\mathrm{k}}$ is $0.063 \sim 0.07 \mathrm{~g} / \mathrm{cm}^{3}$.

Differential Pressure Sticking Tolerance. The mechanism of pressure differential sticking is shown in Fig.2. When the resistance force caused by pressure difference and mud cake can support the weight of entire drill string, the sticking occurs. Which can be expressed by Eq. 11 .

$$
Q=\Delta P \cdot S \cdot f
$$

Where: $Q$ is drill string weight; $f$ is friction coefficient between drill string and mud cake; $S$ is effective contact area between string and mud cake; $\Delta P$ is pressure differential between mud column pressure and formation pressure, which is called critical pressure

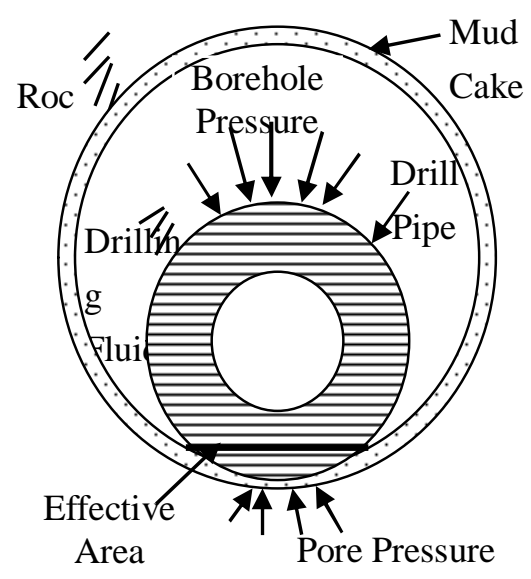

Fig.2 Diagram of differential pressure sticking mechanism differential. By changing Eq.11, Eq.12 can be obtained.

$$
\Delta P_{L}=\frac{Q}{S \cdot f}
$$

By multiple regression analysis, reasonable pressure differential is: $\Delta p_{n} \quad 11 \mathrm{MPa}, \Delta p_{a} \quad 17 \mathrm{MPa}$.

\section{The restriction condition of safety naked hole section}

(1) The restriction condition for preventing borehole collapse

$$
\rho_{\max } \geq \max \left\{\left(\rho_{p \max }+\Delta \rho\right), \rho_{c \max }\right\}
$$

(2) The restriction condition for preventing fracturing formation during drilling

$$
\rho_{\text {bn max }} \leq \rho_{\text {ffmin }}
$$

(3) The restriction condition for preventing differential pressure sticking

$$
\Delta p=0.00981 \times\left(\rho_{\max }-\rho_{p \min }\right) \times D_{n} \leq \Delta p_{N} \text { or } \quad \Delta p_{\mathrm{A}}
$$

\section{Case Study}

Well A is located at Ganggu 1505 well block. The target formations are Permo Carboniferous and Ordovician. The hole configuration of this well was designed basing on pressure prediction and combining the recommended design method and design coefficients. The results of formation pressure prediction are shown in Fig.3. The design process can be described as follow.

Determining the depth of intermediate casing. According to the maximum pore pressure and minimum breakdown (leakage) pressure, the initially determined depth of casing is $1750 \mathrm{~m}$. During running casing: $\Delta p=2.4 \mathrm{MPa}<11 \mathrm{MPa}$, without the danger of sticking casing. At casing shoe: $\rho_{\text {bamax }}=1.41 \mathrm{~g} / \mathrm{cm}^{3}<\rho_{\text {ff }}=1.49 \mathrm{~g} / \mathrm{cm}^{3}$, when killing well, the formation at casing shoe shall not be pressured leaking. The depth of intermediate casing $1750 \mathrm{~m}$ (TVD) meets the requirements. 
Determining the depth of surface casing. The depth of surface casing is $255 \mathrm{~m}$ by trial method. At casing shoe: $\rho_{\text {ba max }}=1.38 \mathrm{~g} / \mathrm{cm}^{3}<\rho_{\mathrm{ff}}=1.61 \mathrm{~g} / \mathrm{cm}^{3}$, during running casing: $\Delta p=0.25 \mathrm{MPa}$. $255 \mathrm{~m}$ (TVD) meets the requirements.

Determining the depth of technical casing 2. The depth of technical casing 2 is $2590 \mathrm{~m}$ calculated by Eq. 15 . During running casing: $\Delta p=10.42 \mathrm{MPa}<11 \mathrm{MPa}$, when killing well: $\rho_{\text {ba max }}=1.10 \mathrm{~g} / \mathrm{cm}^{3}<\rho_{\text {ff }}=1.65 \mathrm{~g} / \mathrm{cm}^{3}$. The depth of technical casing $22590 \mathrm{~m}$ (TVD) meets the requirements.

Determining the depth of production casing. During running casing: $\Delta p=2.45 \mathrm{MPa}<11 \mathrm{MPa}$, when killing well: $\rho_{\text {ba max }}=1.05 \mathrm{~g} / \mathrm{cm}^{3}<\rho_{\text {ff }}=1.67 \mathrm{~g} / \mathrm{cm}^{3}$. The casing runs into bottom meets the requirements.

There is no incident in the process of drilling. The quality of wellbore and cementing are qualified. The design of the hole configuration meets the requirements of safely drilling.

\section{Conclusions}

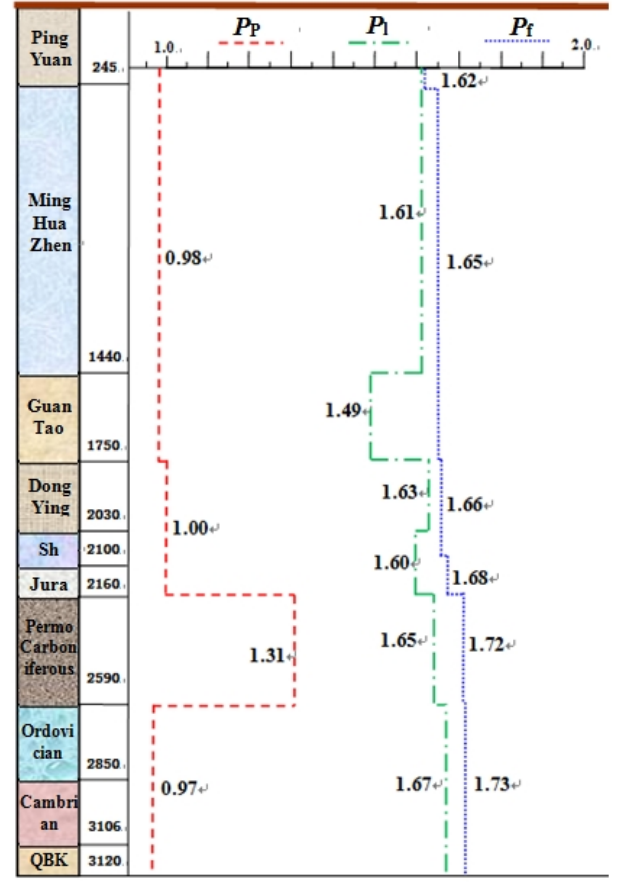

Fig.3 The pressure profiles of Well A

1. When designing hole configuration, the drilling fluid density window becomes narrower by considering leakage pressure. Which can solves the hole configuration design problems existing in special lithology formation, and provides the basis for safely drilling.

2. The hole configuration design coefficients were revised by theoretical model, and value range of the coefficients were obtained. Which provides basis for reasonable hole configuration design.

3. A hole configuration with complex pressure profile and special lithology was designed by considering leakage pressure and changing coefficients. In the process of drilling, there is no incident, Which can prove that the design method and coefficient range is reasonable and effective.

\section{References}

[1] Bu Hongguang, Tang Shizhong, et al. Research and application of Dagang Oilfield casing program optimization[J] . Oil Drilling \& Production Technology, 2011, 33(04): 105-108.

[2] Ke Ke, Guan Zhichuan, et al. An improved casing design method and its application in deepwater drilling[J]. Journal of China University of Petroleum, 2016, 40(02): 76-82.

[3] Guan Zhichuan, Li Chunshan, Zhou Guangchen, et al. A method for designing casing program in deep and superdeep wells[J]. Journal of China University of Petroleum, 2001,25(6):42-44.

[4] Guan Zhichuan, Ke Ke, Lu Baoping. An approach to casing program design with formation pressure uncertainties[J]. Journal of China University of Petroleum, 2009, 33(4): 71-75.

[5] Zeng Yong, Zheng Shuangjin Wu Juncheng, et al. Research of hole configuration optimization design[J]. Journal of Yangtze University (Nat Sci Edit), 2011, 8(09):60-62.

[6] Luo Fengzhi. The application of hole configuration optimization in development well[J]. West-China Exploration Engineering, 2011, 07: 79-81+83. 